\title{
A autoavaliação pode fazer diferença na qualidade da educação: conversando com John MacBeath
}

João Caramelo'

Manuela Terrasêcall

Sonia Maria Portella Kruppalll

I- Universidade do Porto, Porto, Portugal.

Contato: caramelo@fpce.up.pt

II- Universidade do Porto, Porto, Portugal. Contato: terraseca@fpce.up.pt

III- Universidade de São Paulo, São Paulo, SP, Brasil.

Contato: skruppa@uol.com.br

\section{Resumo}

Em uma época em que se tornam avassaladoras as influências das avaliações externas de escolas sobre os sistemas nacionais de educação, a escola pública e a qualidade da educação, é premente ouvir um conceituado e autorizado investigador que defende a necessidade de investir crítica e implicadamente em processos de autoavaliação. John MacBeath, professor emérito da Universidade de Cambridge, e consultor de diversos organismos internacionais, designadamente, Organização para a Cooperação e Desenvolvimento Econômico (OCDE), Organização das Nações Unidas para a Educação, a Ciência e a Cultura (UNESCO) e Organização Internacional do Trabalho (OIT), tem vasta experiência de trabalho e pesquisa em avaliação de escolas e estudos sobre eficácia e melhoria da escola. Na entrevista, John MacBeath refere-se ao projeto europeu desenvolvido no quadro do Programa Sócrates, denominado Avaliação da qualidade na educação escolar, que levou à construção de um instrumento de autoavaliação, o Perfil de Autoavaliação da Escola (PAVE). A sua defesa da relevância e imprescindibilidade da autoavaliação reside na convicção de que qualquer avaliação tem de ser capaz de compreender a cultura da escola, escutar as vozes dos seus protagonistas - os pais, os alunos e os professores -, dar conta de consonâncias e de discordâncias, o que exige um tempo que um visitante/inspetor externo não tem. Para MacBeath, a escola apenas pode promover a sua melhoria a partir do seu interior, pelo trabalho reflexivo e crítico de todos os seus membros. Não menos importante é a sua referência aos efeitos que o Programa Internacional de Avaliação de Alunos (PISA) tem provocado, já que em vez de ajudar a diluir as distâncias entre os países, inspirou a competição e exacerbou as desigualdades, criando uma legião de alunos sem esperança.

\section{Palavras-chave}

Autoavaliação - Avaliação externa - Políticas educativas Comparações internacionais. 


\title{
Self-evaluation can make a difference in the quality of education: dialoguing with John MacBeath
}

\author{
João Caramelo' \\ Manuela Terrasêca" \\ Sonia Maria Portella Kruppal'
}

I- Universidade do Porto, Porto, Portugal. Contact: caramelo@fpce.up.pt

II- Universidade do Porto, Porto, Portugal. Contact: terraseca@fpce.up.pt

III- Universidade de São Paulo, São Paulo, SP, Brasil.

Contact: skruppa@uol.com.br

\begin{abstract}
At a time when the influence of schools external evaluations on national systems of education and on the public school and the quality of education becomes overwhelming, it is urgent to hear a reputable researcher who argues for the need to invest in critical and implicated self evaluation processes. John MacBeath, Emeritus Professor at the University of Cambridge, and consultant for several international organizations, notably the Organisation for Economic Co-operation and Development (OECD), United Nations Educational, Scientific and Cultural Organization (UNESCO), and International Labour Organization (ILO), has extensive experience and research on school evaluation and studies on school effectiveness and improvement. In this interview, John MacBeath refers to the European project developed in the scope of the Socrates program, untitled Quality Assessment in Schools, which led to the construction of a self-evaluation tool, the Self-Evaluation Profile (SEP). His defense of the relevance and indispensability of selfevaluation lays in the conviction that any evaluation must be able to understand the culture of the school, to listen to the voices of school actors - parents, students and teachers -, to give account of agreements and disagreements, which requires a time that a visitor / external inspector does not have. For John MacBeath, the school can only promote its improvement from the inside, by the reflective and critical work of all its members. No less important is the reference to the effects of PISA, since, instead of helping to dilute the distances between countries, it has inspired competition and exacerbated inequalities, creating a legion of no hopers among students.
\end{abstract}

\section{Keywords}

Self-evaluation - External evaluation - Educational policies International comparisons. 


\section{Apresentação}

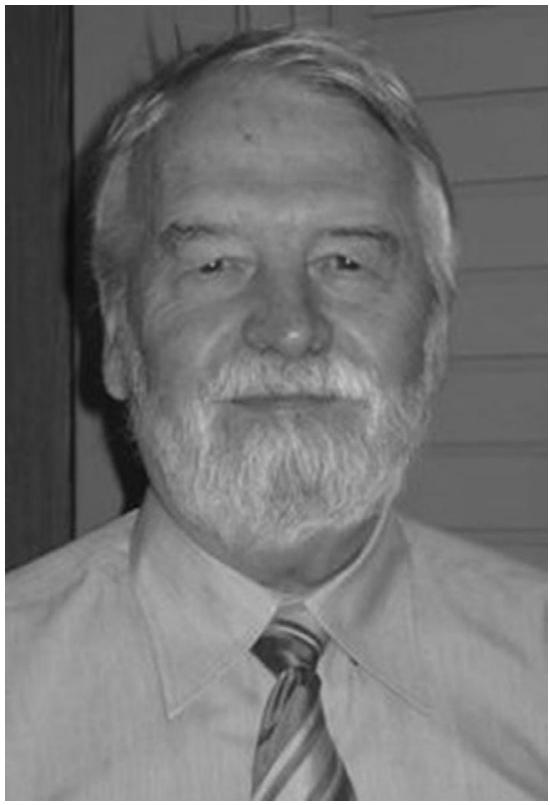

Fonte: arquivos pessoais do entrevistado

John MacBeath é professor emérito da Universidade de Cambridge onde, em 2000, foi nomeado para a cátedra de Educational Leadership. Anteriormente, tinha sido diretor do Centro de Qualidade em Educação na University of Strathclyde, em Glasgow, onde trabalhou em estreita colaboração com a inspeção escocesa no desenvolvimento da autoavaliação e de indicadores de desempenh e na implementação de conselhos escolares. Entre 1997 e 2001, codirigiu com Peter Mortimore um estudo a respeito da eficácia e melhoria da escola, envolvendo 80 escolas. De 1997 a 2001, participou da Task force on standards, de Tony Blair e, entre 1997-1999, no Action group standards, da Escócia.

Em 1997, recebeu a Order of the British Empire por serviços prestados à educação e, em 2009, um Doutoramento honoris causa pela Universidade de Edimburgo. Foi consultor internacional da Comissão Europeia, da OCDE, da UNESCO, da OIT e de várias fundações internacionais. Em 2006, assumiu a presidência do International Congress on School
Effectiveness and Improvement. A sua vasta obra incide sobre temas como participação dos estudantes, autoavaliação da escola, inspeção escolar, liderança e melhoria da escola.

John MacBeath integrou a equipe de um projeto de investigação-ação, de âmbito europeu, desenvolvido no quadro do Programa Sócrates, denominado Avaliação da qualidade na educação escolar. Envolvendo 101 escolas, em dezoito países, todas elas utilizando uma metodologia comum, este projeto construiu um interessante instrumento de autoavaliação, denominado Perfil de Autoavaliação da Escola (PAVE). 0 relatório do projeto, publicado em 2000, foi transformado em livro, A história de Serena: viajando rumo a uma escola melhor. A publicação, que junta ficção e realidade, é dividida em duas partes. A primeira, menos convencional, conta a história a partir do ponto de vista de cinco atores de uma das escolas que integrou o projeto. Deste modo, permite dar conta da diversidade de pontos de vista presentes no processo de autoavaliação, facilitando a compreensão do que é o quotidiano da escola, do que é autoavaliar, de como esses processos se integram nas práticas diárias da escola e como são vivenciados e sentidos pelas pessoas envolvidas, nos seus diferentes papéis. Muito relevante é Serena, personagem que, como aluna, intervém no processo de autoavaliação de sua escola. MacBeath afırma, na introdução à edição portuguesa, que a criação dessa personagem teve como inspiração:

[...] uma aluna que participou na primeira conferência europeia, em 1998, juntamente com professores, diretores de escolas e professores universitários e que fez recordar que no centro de qualquer escola está o aluno, a verdadeira razão da existência das escolas (MACBEATH, 2005, p. 19).

A segunda parte traz a versão mais assente nas normas usuais de uma pesquisa. A leitura do livro pode ser feita a partir de qualquer uma das partes. Em ambas, o perfil 
de autoavaliação da escola é descrito, em suas doze áreas, agrupadas em quatro domínios (resultados, processos ao nível da sala de aula, processos ao nível da escola e o meio). Tal como o prefaciador da edição portuguesa, Natércio Afonso, podemos considerar que a História de Serena ajuda-nos a refletir acerca da complexidade da micropolítica organizacional inerente a qualquer processo de avaliação, bem como pode auxiliar os participantes na avaliação a desenvolverem processos assentes na premissa de que a melhoria da escola se consegue a partir do seu interior e por meio de um trabalho reflexivo e crítico de todos os atores envolvidos.

A Conferência de Viena, realizada em novembro de 1998, destaca o impacto positivo do projeto-piloto original, considerando que:

[...] permitiu sensibilizar as nossas escolas para as questões relativas a sua qualidade e, em quase todas elas, contribuiu para melhorar a qualidade da educação durante o período em que o projeto decorreu (MACBEATH et al., 2005, p. 311).

Encerrada a $1^{\text {a }}$ fase do Programa Sócrates (1999-2000), a $2^{\text {a }}$ acontece com os países envolvidos com outras diretivas que valorizam a avaliação externa. Em Portugal, por exemplo, a autoavaliação surge na legislação em 2002 (Lei 32/2002), por ocasião do início do primeiro ciclo de avaliação externa. A partir de 2006/2007, expande-se a um maior número de escolas, mas sempre enfeudada à realização da avaliação externa. Atualmente, ela continua presente nas escolas, mas aos poucos perde sua vitalidade, subjugada pelas determinações da Inspeção Geral de Educação e, assim, pela avaliação externa.

É necessário voltar um pouco no tempo para circunstanciar o próprio Programa Sócrates no interior da então recém-formada União Europeia.

As comunidades europeias totalizavam três organizações internacionais, criadas em diferentes momentos. A mais antiga, a Comunidade Europeia do Carvão e do Aço (CECA), teve início nos anos cinquenta, destinada a organizar a livre circulação dessas matérias-primas, bem como para proporcionar o livre acesso às fontes de produção para os seis países integrantes: França, Alemanha, Itália, Bélgica, Países Baixos e Luxemburgo. Tais matérias-primas constituíam a base da indústria e do poderio, especialmente da França e da Alemanha. 0 objetivo político subjacente era claramente o reforço da solidariedade franco-alemã, no intuito de afastar o espectro da guerra e a abertura de uma via para a integração europeia. A CECA foi alterada por diferentes tratados que modificaram sua natureza e sua composição.

Em 1957, foi criada a Comunidade Econômica Europeia (CEE) - instituída pelo Tratado de Roma, para estabelecer um mercado comum europeu -, e a Comunidade Europeia de Energia Atômica (CEEA ou Euratom). Essas três comunidades foram fundidas em 1965, pelo Tratado de Bruxelas ${ }^{1}$.

Em 1993, o Tratado de Maastricht fez avançar o escopo de ações da CEE, ao constituir a União Europeia, com políticas que transcendem a economia, tendo dimensões sociais/culturais, nas quais se incluem as políticas de bilinguismo e as educacionais. Cabe destacar que a economia continua sendo o carro chefe da alargada comunidade, constituída por 28 países, reafirmando e ampliando a hegemonia do capitalismo em todos os países e sobre todos os cidadãos europeus, tendo também forte ênfase política. A teoria do capital humano prevalece nas análises da educação e da formação profissional, baseadas numa visão produtivista da educação:

0 capital humano constitui um dos principais factores que determinam $o$ crescimento. Num país europeu típico,

1- Portugal aderiu à Comunidade Econômica Europeia em 1986, sendo um dos últimos países a aderir, antes da queda do muro de Berlim que levou à entrada dos chamados países do leste. 
um ano adicional de escolaridade pode provocar um aumento da produtividade agregada de 6,2\%. No entanto, entre 1995 e 2000, assistiu-se na maior parte dos Estados-Membros a uma diminuição dos investimentos públicos nos sectores do ensino e da formação em termos de percentagem da totalidade das despesas públicas. Devem ser envidados todos os esforços para optimizar o impacto das despesas públicas (COMISSÃO DAS COMUNIDADES EUROPEIAS, 2004).

Em 1995, a UE publicou o livro Branco2 a respeito da educação e formação: Ensinar e aprender. Rumo à sociedade cognitiva, encaminhando as recomendações de outro livro Branco, publicado em 1993: Crescimento, competitividade, emprego - os desafios e as pistas para entrar no século XXI, no qual está sublinhada a importância que reveste, para a Europa, o investimento imaterial, em particular na educação e na investigação.

Em 1997, o Tratado de Amsterdã alargou ainda mais as competências da União Europeia, dando forte tônica às questões de coordenação das políticas de emprego. Da mesma forma, o Conselho Europeu de Lisboa (2000), com o subtítulo para uma Europa da inovação e do conhecimento, traçou linhas de orientação para que se pudesse aproveitar plenamente as oportunidades decorrentes da chamada, à época, a nova economia:

[...] com o intuito de acabar com a calamidade social que representa o desemprego [...] a estratégia previa a adaptação e o reforço dos processos existentes para que o potencial de crescimento económico, de empregos e de coesão social pudesse ganhar toda a sua dimensão - por exemplo, dotando

2- Por meio dos livros brancos, a Comissão Europeia apresenta propostas de ação para os países da comunidade em domínios específicos. Surgem, por vezes, na sequência de livros verdes, cuja finalidade consiste em lançar processos de consulta a nível europeu. a União Europeia de indicadores fiáveis

e comparáveis entre Estados-Membros, para poder tomar as medidas adequadas. (Europa, 2000).

É numa visão economicista do papel da educação e da formação profissional e numa conjuntura econômica de forte desemprego, que métodos quantitativos de aferição dos resultados da educação ganham proeminência, medida que já vinha sendo colocada em prática em muitos países, como é o caso do Brasil, inclusive por sugestão/exigência de organismos internacionais ${ }^{3}$.

Mas a avaliação externa terá também maior impulso a partir das políticas indutivas de outro organismo econômico. Complementarmente à criação das comunidades europeias, formase, em 1960, a Organização para a Cooperação Econômica e Desenvolvimento (OCDE) contando com a participação de países fora do continente europeu: Estados Unidos, Japão, Canadá entre outros, inclusive o Brasil. Em 2000, a OCDE aplicou, pela primeira vez, os exames de um Programa Internacional de Avaliação de Alunos (PISA - Programme for International Student Assessment):

[...] um estudo internacional trienal que tem como objetivo avaliar os sistemas de educação em todo o mundo, testando as habilidades e conhecimentos dos alunos de 15 anos de idade, atualmente sendo aplicado em mais de 70 países ${ }^{4}$.

Com esse instrumento potente, a OCDE vai dar um forte impulso ao processo de

3- No Brasil, a elaboração do sistema nacional de avaliação é anterior ao PISA. A Lei de Diretrizes e Bases da Educação Nacional (Lei Federal $n$ 9494/96) menciona o Sistema Nacional de Avaliação. De fato, o propósito das avaliações externas tem origem em decorrência de exigências do Projeto Nordeste, realizado a partir de um empréstimo junto ao Banco Mundial, na década de 80. Em Portugal, as avaliações externas iniciamse com o Programa de Avaliação Integrada das Escolas que decorreu, em 1999-2001, em apenas algumas escolas do país. A Avaliação Externa das Escolas (AEE) tem sido desenvolvida desde 2007 pela IGE (Inspeção-Geral de Educação).

4- In: <http://www.oecd.org/pisa/aboutpisa/>.Acesso em: dez. 2014. 
avaliações externas praticado pelos sistemas educativos de diferentes países.

Assim, embora o relatório do Programa Sócrates $1^{\text {a }}$ fase reconheça que o Projeto Avaliação da Qualidade na Educação Escolar tenha tido grande significado e, inclusive, tendo recebido uma recomendação do Parlamento Europeu e do Conselho relativa à "cooperação europeia com vista à avaliação da qualidade do ensino básico e secundário" (COMISSÃO DAS COMUNIDADES EUROPEIAS, 2001, p. 16), a $2^{\text {a }}$ fase do Programa Sócrates (2000-2006), no contexto dos livros brancos e dos diferentes tratados, acima mencionados, terá como ideias centrais a promoção da aprendizagem ao longo da vida e o desenvolvimento de uma Europa do conhecimento, dando lugar a atividades que estimulam e facilitam o intercâmbio de experiências, de boas práticas e de inovações, bem como a observação e comparação dos sistemas e das políticas de educação. Em suma, o Programa Sócrates II tem como pano de fundo a avaliação externa.

É neste contexto que a História de Serena pode ser entendida como uma forma de resistência propositiva, um contraponto à maneira de proceder da avaliação externa, que progressivamente passa a ranquear as escolas e os países, na perspectiva de que a competicão será o elemento chave da resolução dos problemas educacionais.

A trajetória de MacBeath revela o seu contato com escolas democráticas, tais como Summerhill e com as escolas sem paredes de Filadélfia. Há relatos de sua participação na criação de uma escola livre junto a uma comunidade de jovens de baixa renda de Glasgow, a maior cidade da Escócia, onde MacBeath trabalhou junto da inspeção. Isso ajuda a compreender a sua ênfase no diálogo, considerado o coração da autoavaliação escolar, impossível de ser realizada sem a participação dos alunos e de suas famílias.

Da extensa obra de Macbeath destacamos A história de Serena: viajando rumo a uma escola melhor, porque nos coloca desafıos muito interessantes, como a relevância e imprescindibilidade da participação na avaliação das escolas, de professores, alunos e pais enquanto atores-chave no palco do sistema educativo, para que a mudança da escola ocorra através da autoavaliação partilhada. Esses são desafios instigantes para refletirmos a respeito do momento atual, em que a maioria dos sistemas educativos, sob o lema das avaliações externas, veleja em ventos opostos.

\section{Referências}

COMISSÃO DAS COMUNIDADES EUROPEIAS. Comunicação da Comissão ao Conselho e ao Parlamento Europeu: perspectivas financeiras 2007-2013. Bruxelas: Comissão das Comunidades Europeias, 2004. p. 8. Disponível em: <http://ec.europa.eu/ transparency/regdoc/rep/1/2004/PT/1-2004-487-PT-F1-1.Pdf>. Acesso em: dez. 2014.

COMISSÃO DAS COMUNIDADES EUROPEIAS. Relatório final da Comissão sobre a execução do Programa Sócrates 19951999. Bruxelas: Comissão das Comunidades Europeias, 2001.

Europa. Debate Europe. Estratégia de Lisboa: Conselho Europeu extraordinário de Lisboa (Março de 2000): para uma Europa da inovação e do conhecimento. Lisboa: [s. n.], 2000. Disponível em: <http://www.drapc.min-agricultura.pt/base/geral/files/ estrategia_lisboa.pdf>. Aceso em: dez. 2014.

MACBEATH, John et al. A história de Serena: viajando rumo a uma escola melhor. Porto: ASA, 2005.

OCDE. About PISA. Disponível em: <http://www.oecd.org/pisa/aboutpisa/>. Acesso em: dez. 2014.

UNIVERSITY OF CAMBRIDGE. Perfil de John MacBeath. Disponível em: <http://www.educ.cam.ac.uk/people/staff/ macbeath/\#profile>. Acesso em: dez. 2014. 


\section{ENTREVISTA}

Gostaríamos de conhecer algumas de suas opiniões a respeito da trajetória que vem sendo percorrida pela autoavaliação. Mas, em primeiro lugar, gostaríamos de ouvi-lo a respeito de sua própria trajetória profissional e de como iniciou no campo da avaliação, com que tipo de preocupação e com que intenções tem trabalhado nessa área.

Faz muito tempo que tudo começou e demoraria demasiado fazer um relato completo, mas vou procurar ser sucinto. Eu trabalhava com a inspetoria da Escócia, isso lá pelo final da década de 1960, começo da de 1970. Realizava uma série de trabalhos para a inspetoria e para o então inspetor-chefe. Ele disse que queria mudar da inspeção escolar para a autoavaliação e essa foi, provavelmente, a primeira vez que, de fato, explorei esse tema com alguma profundidade. 0 que lhe sugeri, então, foi que coletássemos dados junto a jovens (crianças), a pais e a professores e isso constituiria a base de uma autoavaliação. De início, mostrou-se um pouco cético, mas disse: "Vamos tentar isso pelo menos em cinco escolas: escolas primárias, escolas especiais e escolas secundárias. Vamos só experimentar e ver o que eles têm a dizer". Então, trabalhei com essas cinco escolas e levei os dados para ele, que ficou tão impressionado com o que resultara que disse: "Seria prematuro passarmos daí para uma política em larga escala, mas façamos isso com, digamos, 10 escolas de modo a ter uma base melhor para confiarmos nesse processo." Então foi o que fiz e de novo os resultados foram ótimos. Embora tivesse ficado muito satisfeito, ele disse: "Talvez 10 não seja o bastante, vamos tentar com 25". Então, fizemos a mesma coisa com 25 escolas e como continuamos a obter muitos bons resultados, isso já era suficientemente forte para se tornar uma política na Escócia. Então, esses resultados foram publicados em três versões (para escolas primárias, secundárias e especiais) como Indicadores de ethos: levando em conta as opiniões de alunos, pais e professores. Foi assim que se construiu o fundamento da autoavaliação e, então, o Sindicato Nacional dos Professores da Inglaterra achou que era uma ótima ideia repetir o processo na Inglaterra. A seguir, passamos por processo semelhante na Alemanha, com a Fundação Bertelsmann, e foi indo assim por diante... Esse foi o começo da história e eu podia continuar falando, mas vou parar por aqui.

A seguir, teve a oportunidade de desenvolver um projeto europeu no âmbito do Programa Sócrates, que ajudou a expandir e a obter uma difusão mais ampla de seu trabalho e suas ideias sobre autoavaliação. Gostaríamos de compreender os fundamentos desse projeto, o propósito e de que modo procurou concretizá-lo.

A história começou com um projeto extremamente interessante e surpreendente. Andres Hinckel, então diretor da divisão de avaliação da Comissão Europeia, chamou-o de $O$ belo projeto. Éramos quatro: eu, do Reino Unido, Michael Schratz, da Áustria, Lars Bo Jacobsen, da própria Comissão, e Denis Meuret, da França. Nós quatro trabalhávamos bem em conjunto. Pode-se dizer que estávamos bem afinados. Sabíamos o que queríamos e queríamos recomeçar com aqueles três elementos chave: pais, alunos e professores. E como você deve saber, criamos um formulário simples com doze indicadores chave que deveriam fornecer a base para as conversas a respeito da avaliação nas escolas. Esse perfil de autoavaliação (Self Evaluation Profile, SEP) consistia de doze afırmações chave a respeito de aprendizagem, ambiente escolar, liderança e relações com a comunidade que os três elementos chave avaliariam relativamente à: a) importância e b) prática. A divergência entre essas tornava-se então tema de discussão e planejamento futuro.

Tudo isso, evidentemente, foi escrito no livro a respeito da autoavaliação nas escolas europeias. Só nos surpreendemos muito com o 
quanto cada um se envolveu, quando reunimos jovens com professores e pais e os jovens começaram a apresentar um ponto de vista que se mostrava tão perspicaz e tão diferente daquilo que os professores, ou os coordenadores, estavam enxergando. A conversa dirigiase diretamente ao cerne do que faz uma boa escola, do que faz bons professores, do que faz uma boa aprendizagem, sempre exigindo evidências: “o que lhe permite dizer isso?”como um dos protocolos para o estabelecimento de um fundamento comprobatório, ao invés de simples opinião.

Um dos documentos produzidos na sequência daquele programa foi a declaração de Viena. Trata-se realmente de um documento revelador de uma concepção, com que nos identificamos, de como se pode pensar e fazer autoavaliação, mas que, provavelmente, não traduz o que a autoavaliação pretende ser hoje em dia. Por exemplo, para nós, é curioso não ter encontrado na declaração de Viena referência alguma à avaliação externa. Mas, hoje em dia, a avaliação externa contraataca, está tendo uma influência muito mais ampla sobre a maneira como se concebe a avaliação escolar. Gostaríamos de conhecer sua impressão sobre isso.

Gostei da expressão que você usou. Dá um bom título: A avaliação externa contraataca! Isso se baseia em uma tal falácia que, digamos, um inspetor visitante, ou alguma outra pessoa, pode vir por um curto período e ser capaz de compreender o ethos, a cultura e a dinâmica da escola. E quando escrevemos no projeto europeu a respeito do amigo crítico, esse amigo crítico é aquele que chega com a premissa: "buscar entender antes de mais nada”. Esse é seu primeiro dever como visitante externo: compreender a cultura, compreender as vozes da escola, estar em sintonia com as harmonias e as dissonâncias. E isso leva muito tempo, compreender a cultura. Assim, uma visita curta, de dois, três, quatro ou cinco dias não basta para mergulhar naquela cultura. E temos muitos dados a respeito disso - de Hong Kong, onde continuo trabalhando, da Nova Zelândia, onde muito recentemente preparei um relatório para a OCDE. Em todos esses lugares, reconhecese que não basta irmos a uma escola, observar uma classe, às vezes por 15 ou 20 minutos, como na Inglaterra, se desejamos realmente obter uma compreensão da cultura da escola. Claro que o olhar externo é importante, mas ele precisa fundamentar-se, antes de mais nada, numa compreensão do olhar interno. E isso pode ser muito desafiador, não só aceitar o olhar interno, mas com uma boa orientação crítica amigável começar a examinar, a falar a respeito e a complementar aquele olhar interior. Então, penso que o que fizemos no relatório da OCDE na Nova Zelândia, por exemplo, aproximou-se bastante daquilo que deve ser o relacionamento interno-externo, e foi assim também em Hong Kong. Esses dois lugares foram os que mais se aproximaram de conseguir o estabelecimento de relações desse tipo. Não conseguiram fazer isso da maneira absolutamente correta. Mas estão muito mais perto de construir sua avaliação externa embasada primeiro sobre a avaliação interna, e na Inglaterra ainda não se conseguiu esse relacionamento. Por aproximadamente três décadas, Ofsted (o órgão de inspeção) continua tentando e eles continuam fazendo avaliações, mas se você falar com qualquer escola, ou qualquer professor, eles simplesmente lhe dirão como é estreita a visão política pelo fato de não captar a dinâmica muito complexa de que uma escola é feita.

Estamos sentindo que as escolas sofrem tal pressão com o ranqueamento, os exames nacionais de seus alunos, que vão esquecendo o que a autoavaliação poderia ser, submetendo à avaliação externa o que esta pretende ver, e isso são principalmente os resultados dos alunos, o progresso das escolas, os escores médios nos exames nacionais. De modo que nossa sensação é que a pressão nacional e internacional por resultados está 
influenciando enormemente sobre o que a autoavaliação está se tornando. 0 que pensa a respeito disso?

Você tem toda a razão. Trata-se, na verdade, de um problema global e aí a OCDE desempenha papel da maior importância. 0 vício da OCDE em tabelas comparativas entre países significa que nenhum país quer estar lá embaixo nos últimos postos, não quer estar no $11^{\circ}, 12^{\circ}$ ou $13^{\circ}$ na tabela do campeonato. Então, a pressão se exerce sobre as escolas para que tenham bom desempenho, sobre o diretor da escola ou sobre o coordenador, para que apresentem resultados. Consequentemente, a pressão chega aos professores, para que trabalhem mais. E isso afeta todos os países da OCDE e, mais do que isso, atinge os países que não são da OCDE. Algumas semanas atrás, esteve em Cambridge Andreas Schleicher ${ }^{5}$ que é diretor da OCDE e os delegados da Conferência o questionaram. Pessoas de cerca de quinze diferentes países que lhe deram muito trabalho. Andreas Schleicher é atualmente o guru global, ele está por toda a parte. Se você quiser agendar um encontro para ele vir falar, ele terá de consultar sua agenda do ano que vem ou dos próximos três anos, e assim ele anda por toda a parte pregando o evangelho dos dados comparativos, embora diga que se você ler cuidadosamente os documentos da OCDE, verá que eles também lidam com muitos dados atitudinais e também oferecem muitas advertências relativas aos resultados medidos. Assim, há muitas coisas ali, nos relatório da OCDE, que os formuladores de políticas tendem a não ver ou às quais não dão muita importância, de modo que Andreas Schleicher culparia amplamente os formuladores de políticas pela seleção tendenciosa que fazem do que há nesses relatórios da OCDE e por pressionarem as escolas mediante a limitação da agenda com ênfase naquilo que é mais fácil de medir. Assim, embora ele próprio tenha uma

5- Andreas Schleicher é diretor de educação e competências e consultor especial sobre política educacional do secretário-geral da Organização para Cooperação e Desenvolvimento Econômico (OCDE). visão muito mais ampla a respeito disso, não é o que acontece quando os formuladores de políticas agem dessa maneira, desprezando indicações que resultariam mais trabalhosas e gerariam pressões sobre aqueles formuladores de políticas. Então, é muito difícil para qualquer que seja o país ficar imune a essa pressão. 0 perigo é que em vez de diminuir o fosso, que é a retórica da política em vários países, o resultado da competição inspirada no PISA é na verdade aumentar a diferença, porque o investimento é feito nos que têm maior probabilidade de apresentar resultados elevados. Então, a eles são oferecidos os melhores professores e ignoramse aqueles que alguns professores na Inglaterra têm descrito como os sem esperança.

Podemos considerar que isso se relaciona com a mudança do papel do Estado na regulação da política educacional. Encontramos agora um Estado mais orientado para a avaliação ou um Estado que está ali apenas para verificar se, no fim, teremos os resultados esperados. Também gostariamos de escutá-lo a respeito do tipo de efeitos que tem essa reconfiguração do Estado na área da educação, especificamente nas políticas de avaliação, nas políticas de autoavaliação.

Interessante voltar algumas décadas atrás. Os ministérios de educação, as secretarias de estado para a educação no Reino Unido não consideravam ser sua função envolver-se com a política escolar. Isso ficava por conta das escolas e das autoridades locais ${ }^{6}$. Creio que é provável que a mudança tenha ocorrido por volta do regime Thatcher, quando o governo

6- Antes de 10 de abril de 2009, as Autoridades Locais de Educação (Local Education Authorities, LEAs) eram os organismos responsáveis pela administração local do setor estatal de serviços educacionais. Os deveres em relação à estrutura da educação cobriam a indicação e manutenção dos dirigentes; atuar como empregador das equipes docente e não docente (embora pudessem não ter esse direito relativamente a escolas confessionais, voluntárias ou de fundações); coordenar os processos de admissão da escola; fixar as datas para o ano letivo; e prover planos educacionais, comportamentais e financeiros para as escolas mantidas. As LEAs não existem mais e tornaram-se o DfE (Department for Education) em 12 de maio de 2010. 
começou a ter grande interesse pela educação baseada essencialmente numa perspectiva econômica. Não se podia mais confiar nos professores, obviamente, por estarem por demais interessados em si mesmos. Não se podia confiar nas próprias escolas, de modo que se devia intervir sobre o que acontecia nas escolas com vistas à sua contribuição para a economia. Há muita mitologia em torno disso. Embora se leia, e vocês certamente leram, muita literatura a esse respeito, a respeito do impacto econômico de ter crianças mais competitivas em matérias essenciais etc., é escassa a evidência de que isso tenha um retorno econômico. 0 problema é que toda essa literatura a respeito da interface educaçãoeconomia - e há imensa literatura sobre isso - é complexa demais para que os formuladores de políticas se incomodem com ela. 0 que eles dizem é: "Deem-me algo simples! Lembrem-se dos bons velhos tempos quando nos ensinavam e todos nós aprendíamos, voltemos àqueles dias em que as crianças eram muito mais obedientes e aprendiam sua matemática e adoravam". Assim, há todas essas mitologias, para começar, a respeito do que costumava existir e porque tínhamos um sistema tão maravilhoso no passado. Assim, o modo como costumávamos ser é erigido como o ideal pelo qual devemos lutar. Mas a politização da educação cresceu amplamente com a acessibilidade dos dados comparativos e foi aí que ela começou a ter uma influência tão insidiosa, porque descobrimos que podíamos medir, especialmente se você toma a matemática; a matemática é ótima porque dela se pode pegar uma porção de bons números a partir dos quais comparar o efeito da escola com o efeito externo. Claro que isso é muito mais difícil com arte, línguas e outras matérias. Mas se você toma a matemática, então os pesquisadores dirão: "Sim, você pode usar esse tipo de dados comparativos por serem menos contaminados por influências externas". Então, poderemos ter uma medida de quão bem as escolas estão produzindo resultados. Apesar do conselho de muitos acadêmicos, eu inclusive, que éramos consultores do governo, os chamados gênios da política simplesmente não escutaram, e não quiseram saber, e não compreenderam por estarem sob uma tal pressão da competição, nacional e internacionalmente, e - para de novo, só por um momento, falar da Inglaterra - quando lá se livraram em larga escala das autoridades locais e chegaram às escolas individuais, deixou de haver essa intervenção de intermediários, passando então a ser escola contra escola. E considero que este é o maior problema. Quando você elimina essa camada intermediária entre governo e escolas, exacerbando assim a competição. A ironia é que na mão esquerda tem-se toda essa pressão competitiva por dados sobre notas e resultados, mas, se olhamos para a mão direita, há inúmeras publicações da OCDE a respeito da necessidade de mudança radical, em prol da educação permanente e da sociedade da aprendizagem.

Estando do lado da resistência, do lado dos que acreditam ser possivel e ser importante defender uma política de educação pública, na defesa de iguais oportunidades de aprendizagem para todos, e que a autoavaliação pode ser feita de outro modo, que desafios você considera importante enfrentar para resistir e propor algumas alternativas no modo como se conduz a autoavaliação?

Bem, creio que parte da resposta é evitar aquilo de que Jonathan Swift $^{7}$ falou como sendo "os da extremidade grossa e os da extremidade delgada”, ou isto ou aquilo, a oposição entre autoavaliação e inspeção. Creio que o argumento deve estar à meia distância de dizer "claro que cremos que um olhar externo, aquela perspectiva externa, é muito importante e jamais quereríamos descartar alguma forma de inspeção externa, ou moderação externa, porque as escolas podem tornar-se muito

7- Esta é uma referência às Viagens de Gulliver, de Jonathan Swift, livro no qual um dos temas é a disputa a respeito de ovos, entre os liliputianos, que preferiam abrir seus ovos quentes pela extremidade mais delgada, e os blefuscudianos, que preferiam abri-los pela extremidade mais grossa. 
isoladas e podem tornar-se muito satisfeitas consigo mesmas, e a autoavaliação pode, às vezes, ser apenas um autoelogio”. Então, o ataque contra a autoavaliação da escola devese muitas vezes a que tem sido demonstrado que as escolas, às vezes, não são muito boas para administrar sua própria autoavaliação, para "se conhecerem a si mesmas". Esse é seu ponto fraco, seu calcanhar de Aquiles. Então, o argumento deve ser, como foi em Hong Kong, como foi na Nova Zelândia e agora, até certo ponto, no Reino Unido, avaliação proporcional. Creio que esse é o caminho. Ou seja, se você tem uma autoavaliação fortemente implantada, ou realmente conhece a própria escola e é muito rigoroso, então você não depende de ninguém e não precisa de grande ajuda de um órgão externo, mas ao mesmo tempo uma visita sua de vez em quando será bem-vinda. No outro extremo, você tem escolas que, na verdade, estão se enganando, ainda não estão prontas para isso, e precisam de muito mais ajuda externa, talvez não muita pressão externa, mas certo apoio externo para serem capazes de fazer efetivamente sua autoavaliação. Assim, creio que, na verdade, a avaliação proporcional* é por onde se deve ir, e eu diria que todos nós precisamos disso. Mas precisamos também de algo mais, não só uma exigente e rija inspeção numa ponta e um toque suave na outra, mas sim, alguma coisa intermediária. As escolas que estão realmente se esforçando precisam receber um apoio crítico amigável. Então, não é para se chegar dizendo: "Vocês não estão fazendo direito, vocês vão ser castigados, haverá sanções, podemos chegar a suspender suas atividades", não é por aí. 0 caminho a percorrer com escolas que estão se esforçando é darlhes o apoio de um amigo crítico muito forte e perspicaz. É nessa direção, creio eu, que têm caminhado a Nova Zelândia, particularmente, e Hong Kong.

É possível que os professores estejam aprendendo como fazer isso e enfrentando, ao mesmo tempo, uma porção de outras pressões.
Portanto, talvez não seja uma questão de não existência de uma cultura de autoavaliação nas escolas, mas antes, que a autoavaliação, às vezes, se torna uma rotina a mais, algo que os professores percebem como mais trabalho, a que não atribuem um sentido precisamente por causa daquelas pressões. 0 que diria acerca disso?

Se você está sob pressão, é realmente quase uma conspiração fazer os professores trabalharem mais, e mais, e mais, e eles não têm tempo para se preocupar com a autoavaliação, simplesmente entrando, fazendo o serviço, indo para casa, antes conduzidos do que conduzindo. Temos escrito muito a respeito disso. Há um relatório que vai ser publicado em janeiro, com o Sindicato Nacional dos Professores, a respeito dessa enorme quantidade de pressão que há nas escolas. Uma das principais conclusões desse relatório é o preço pago pelas crianças com necessidades especiais. Como elas puxam para baixo os resultados globais da escola, as escolas podem recusar-se a admiti-las, ou limitar o número delas, ou pedir que fiquem em casa nos dias de inspeção ou de exames. Além disso, se você diz aos professores: "O que queremos que vocês façam é que se envolvam com a autoavaliação", a resposta provavelmente será "Não! Não! Isso ainda é uma coisa a mais. Estamos satisfeitos com que a cada três ou quatro anos venha uma inspeção, a gente se prepara para uma inspeção, mas não venham nos pedir para investir mais tempo nessa coisa chamada autoavaliação, vai ser mais uma fonte de pressão". E, é claro, isso alimentará os preconceitos dos formuladores de políticas, os que são contra a autoavaliação. Eles dirão "É isso aí, você viu? Os professores realmente não querem fazer isso!” E há uma grande quantidade de evidências de que os professores não querem isso por lhes ser apresentado num clima em que é encarado como se quisessem envolvê-los em trabalho extra. Onde vimos um processo de mudança, especialmente em Hong Kong, focamos na camada dirigente da 
equipe, os 10\% se você quiser, que realmente implantaram a autoavaliação em sua prática rotineira. Conseguimos então que esses coordenadores e esses professores fossem os que então trabalharam com outras escolas dizendo: "Vejam! Quando vocês tiverem conseguido uma autoavaliação bem firme, então os professores terão realmente mais poder, os jovens serão mais felizes, a escola será um lugar melhor, os pais gostarão dela, quando vocês conseguirem uma autoavaliação muito firmemente implantada". Mas isso poderá ser somente $10 \%$ ou $15 \%$ de todas as escolas e no outro extremo você terá aqueles que simplesmente não querem ter nada a ver com isso. Assim, a política em Hong Kong foi conseguir que esses 10\% das escolas conduzissem o processo, apoiando-se na experiência desses professores e desses coordenadores, o que se mostrou muito mais digno de crédito do que eu lhes dizer como aquilo poderia ser maravilhoso, porque, o que sei eu? Sou um docente de Cambridge, não sofro a pressão diária de uma sala de aula. Desse modo, serão professores ajudando professores e creio que esta é realmente a chave para isso, onde você conseguiu alguns exemplos de boa prática, você pode usar essas pessoas para ajudar seus colegas. Meus relatórios de avaliação destacam os modos imaginativos com que estudantes, quando têm a oportunidade, contribuem de maneira marcante para melhorar suas escolas, desde o trabalho com cartazes nas áreas de entrada e nos corredores, até a avaliação e recomendações a respeito da qualidade do ensino ou atuando como membros dos Grupos de Aperfeiçoamento da Escola (School Improvement Groups) junto com a equipe técnica, e assumindo papéis de liderança na melhora da escola. Houve uma escola em que um aluno de dezesseis anos foi encarregado da autoavaliação, assessorando a respeito de alterações nos horários e rotinas da escola e nas relações com os pais. Ele assistia às reuniões de trabalho que eu fazia em Hong Kong e trouxe seu coordenador com ele para uma das conferências que eu iria fazer.
Uma última pergunta: uma temática bastante presente nos seus trabalhos é a da inspetoria. As relações entre o quadro de inspetores e as escolas também está mudando. Que tipo de relações inspetoria-escolas seria importante cultivar para melhorar a autoavaliação e, em sua opinião, que papéis poderá a inspetoria desempenhar nesses processo.

Creio que a chave é a oportunidade que possa existir de trabalhar com inspetores, particularmente no aspecto pedagógico, em especial com pessoas que tenham sido professores. Não sei em que medida existe em Portugal um desenvolvimento profissional continuado para essas pessoas, mas onde estive envolvido, na Alemanha e na Polônia, por exemplo, grande parte do trabalho que estão fazendo, na Polônia, por exemplo, com seus inspetores, é levá-los a compreender como você vê e o que pode ver quando você possui o que chamamos de olhar esclarecido. Isso diz respeito a como você entra numa escola, o modo como você aprende a enxergar as coisas que são importantes e as que mais se destacam, e como você aprende a escutar mais do que sempre falar; e como você suspende os seus juízos e aprende a fazer esses juízos quando há maior compreensão da cultura e das relações. Assim, o desenvolvimento profissional com essas pessoas é absolutamente crucial. Mesmo que estejam sob muita pressão política, quando têm uma compreensão mais ampla de como enxergar o que é mais importante e o que mais se destaca na escola, saberão como então assessorar a equipe sobre a autoavaliação. Penso que o trabalho que fiz em diversos países com a inspetoria é a chave para isso. Por exemplo, num curso de um dia de duração, pode-se mostrar a elas vários exemplos de sala de aula, pedir que façam seus juízos de valor e os compartilhem, discutam seus critérios e, a seguir, numa discussão ampla comprovem mais profundamente o que pode ou não pode ser visto e o que, às vezes, está oculto do juízo apressado e que outras 
fontes de evidência podem proporcionar um quadro mais completo. Não sei até que ponto Portugal desejará empenhar-se nesse tipo de desenvolvimento profissional de inspetores, mas é crucial que eles enxerguem o alcance da mudança, talvez visitando outros países em que a autoavaliação funciona particularmente bem ou, em Portugal mesmo, se for possivel identificar algumas escolas realmente de ponta com uma boa autoavaliação, bem como bons resultados, e então promover a visita desses inspetores para falar com esses professores e com as crianças nessas escolas que estejam, de fato, sendo bem-sucedidas.

\section{Publicações em língua portuguesa}

MACBEATH, John et al. A história de Serena: viajando rumo a uma escola melhor. Porto: ASA, 2005.

\section{Publicações em língua inglesa}

\section{Livros}

MACBEATH, John. Connecting leadership and learning: principles for practice. New York: Routledge, 2009.

MACBEATH, John. Education and schooling: myth, heresy and misconception. London: Routledge, 2013.

MACBEATH, John (Ed.). Effective school leadership: responding to change. London: Sage, 1998.

MACBEATH, John. Learning in and out of school: the selected works of John MacBeath. London: Routledge, 2012.

MACBEATH, John. School inspection and self-evaluation: working with the new relationship. London; New York: Routledge, 2006.

MACBEATH, John. Schools must speak for themselves: the case for school self-evaluation. London: Routledge, 1999.

\section{Livros em parceria}

MACBEATH, John; BANGS, John; GALTON, Maurice. Reinventing our schools: principles, pedagogy and policy imperatives. New York: Routledge, 2011.

MACBEATH, John; CHENG, YC. (Eds.). Leadership for learning: international perspectives. Rotterdam: Sense, 2008.

MACBEATH, John et al. Improving learning: how to learn in classrooms, schools and networks. London: Routledge, 2007.

MACBEATH, John et al. Schools on the edge: responding to challenging circumstances. London: Paul Chapman, 2006.

MACBEATH, John et al. Self-evaluation in European schools: a story of change. London; New York: Routledge Falmer, 2000.

MACBEATH, John; GALTON, Maurice. Teachers under pressure. London: Sage, 2008.

MACBEATH, John; GALTON, Maurice; BANGS, John. Reinventing schools, reforming teaching: from political visions to classroom reality. London: Routledge, 2010.

MACBEATH, John; MCGLYNN, Archie. Self-evaluation: what's in for schools? London; New York: Routledge Falmer, 2002.

MACBEATH, John; MOOS, Lejf (Eds.). Democratic learning: the challenge to school effectiveness. London; New York: Routledge Falmer, 2004.

MACBEATH, John; MORTIMORE, Peter (Eds.). Improving school effectiveness. Buckingham: Open University Press, 2001.

MACBEATH, John; SUGIMINE, Hidenori (Eds.). Self-evaluation in the global classroom. London; New York: Routledge Falmer, 2003. 
MACBEATH, John; TOWNSEND, Tony (Eds.). International handbook of leadership for learning. Parts 1-2. Rotterdam: Springer, 2011.

MACBEATH, John; YOUNGER, Mike (Eds.). A common wealth of learning: millennium development goals revisited. New York: Routledge, 2013.

\section{Artigos de periódicos científicos}

MACBEATH, John. A story of change: growing leadership for learning. Journal of Educational Change, v. 7, n. 1/2, p. 33-46, 2006.

MACBEATH, John. Border crossings. Improving Schools, v. 12, n. 1, p. 81-92, 2009.

MACBEATH, John. Close encounters of a congenial kind. Cambridge Journal of Education, v. 41, n. 3, p. 369-381, 2011.

MACBEATH, John. Constructing sites for learning and teaching. Education Review, v. 21, n. 1, p. 22-30, 2008.

MACBEATH, John. Developing international education indicators. Scottish Educational Review, v. 25, n. 1, p. 46-52, 1993.

MACBEATH, John. Education of teachers: the English experience. Journal of Education for Teaching: International Research and Pedagogy, v. 37, n. 4, p. 377-386, 2011.

MACBEATH, John. Finding a voice, finding self. Educational Review, v. 58, n. 2, p. 195-207, 2006.

MACBEATH, John. Leadership as a subversive activity. Journal of Educational Administration, v. 45, n. 3, p. 242-264, 2007.

MACBEATH, John. Leadership as distributed: a matter of practice. School Leadership and Management, v. 25, n. 4, p. 349-366, 2005.

MACBEATH, John. Leading learning in the self-evaluating school. School Leadership \& Management, v. 28, n. 4, p. 385-399, 2008.

MACBEATH, John. Learning-school, home and neighborhood. Hume Papers on Public Policy, v. 8, n. 4, p. 1, 2000.

MACBEATH, John. New relationships for old inspection and self evaluation in England and Hong Kong. International Studies in Educational Administration, v. 34, n. 2, p. 2-18, 2006.

MACBEATH, John. No lack of principles: leadership development in England and Scotland. School Leadership \& Management, v. 31, n. 2, p. 105-121, 2011.

MACBEATH, John. Putting the self back into self-evaluation. Improving Schools, v. 7, n. 1, p. 87-91, 2004.

MACBEATH, John. Recruitment and retention of senior school leaders: meeting the challenge. European Educational Research Journal, 8(3), p. 407-417, 2009.

MACBEATH, John. Speaking up for teachers. Education Review, v. 24, n. 2, p. 19-29, 2011.

MACBEATH, John. Stories of compliance and subversion in a prescriptive policy environment. Educational Management, Administration, \& Leadership, v. 36, n. 1, p. 123-148, 2008.

MACBEATH, John. Stories of hope in an age of foolishness. Education Review, v. 21, n. 1, p. 10, 2008.

MACBEATH, John. The development of student study centers to improve homework and learning in Scotland. Childhood Education, v. 74, n. 6, p. 383-386, 1998.

MACBEATH, John. The talent enigma. International Journal of Leadership in Education, v. 9, n. 3, p. 183-204, 2006.

MACBEATH, John. Time for the vulnerable, patient leader. School Leadership Today, v. 4, n. 4, p. 56-63, 2012. 
MACBEATH, John. BANGS, John. Collective leadership: the role of teacher unions in encouraging teachers to take the lead in their own learning and in teacher policy. Professional Development in Education, v. 38, n. 2, p. 331-343, 2012.

MACBEATH, John et al. Valuing pupils' views in Scottish schools. Educational Research \& Evaluation, v. 6, n. 4, p. 281-316, 2000.

MACBEATH, John; GALTON, Maurice. Balancing the workload equation in English primary schools: a continuing story? Asia-Pacific Journal of Teacher Education, v. 38, n. 4, p. 301-315, 2010.

MACBEATH, John; JULL, Stephen; SWAFFIELD, Sue. Changing perceptions is one thing: barriers to transforming leadership and learning in Ghanaian basic schools. School Leadership \& Management, v. 34, n. 1, p. 69-84, 2014.

MACBEATH, John; MOOS, Lejf. First editorial. Educational Assessment, Evaluation \& Accountability, v. 21, n. 1, p. 1-4, 2009.

MACBEATH, John; O'BRIEN, Jim; GRONN, Peter. Drowning or waving? Coping strategies among Scottish head teachers. School Leadership \& Management, v. 32, n. 5, p. 421-437, 2012.

MACBEATH, John; ODURO, George K. T. Traditions and tensions in leadership: the Ghanaian experience. Cambridge Journal of Education, v. 33, n. 3, p. 441-455, 2003.

MACBEATH, John; PEDDER, David. Organizational learning approaches to school leadership and management: teachers' values and perceptions of practice. School Effectiveness and School Improvement, v. 19, n. 2, p. 207-224, 2008.

MACBEATH, John; PEDDER, David; JAMES, Mary; How teachers value and practice professional learning. Research Papers in Education, v. 20, n. 3, p. 209-243, 2005.

MACBEATH, John; SWAFFIELD, Sue. Embedding learning how to learn in school policy: the challenge for leadership. Research Papers in Education, v. 21, n. 2, p. 201-215, 2006.

MACBEATH, John; SWAFFIELD, Sue. School self-evaluation and the role of a critical friend. Cambridge Journal of Education, v. 35, n. 2, p. 239-252, 2005.

MACBEATH, John; SWAFFIELD, Sue; FROST, David. Principled narrative. International Journal of Leadership in Education, v. 12, n. 3, p. 223-237, 2009. 